\title{
Gas-to-electricity investment planning for power system stability improvement and environmental sustainability in Nigeria
}

\author{
Oludamilare B. Adewuyi ${ }^{1,}{ }^{*}$, Mark. K. Kiptoo ${ }^{1}$, Ayodeji F.Afolayan ${ }^{2}$, Ayooluwa .P. Adeagbo ${ }^{3}$ and Tomonobu Senjyu ${ }^{1}$ \\ ${ }^{1}$ Faculty of Engineering, University of the Ryukyus, 1 Senbaru, Nishihara-cho, Nakagami, Okinawa, 903-0213, Japan \\ ${ }^{2}$ Institute for Sustainable Development, First Technical University, Ibadan, Oyo, 200253, Nigeria \\ ${ }^{3}$ Faculty of Engineering, Adeleke University, Ede, Osun, 232101, Nigeria
}

\begin{abstract}
Power outage is a prominent feature of the current Nigerian power system. However, a properly planned energy sector can help the nations quest for energy sustainability and economic development. Techno-economic assessment of the Nigerian energy facilities for efficient gas-to-grid power integration is presented in this paper using the particle swarm optimization algorithm (PSO) for solving a voltage stability-constrained optimal power flow model on Matlab environment. Investment in gas-fired DG technology can be an economic and sustainable approach for reducing the detrimental effects of gas-flaring practices of the petroleum industries on the environment. The technical benefits such as voltage profile improvement and voltage stability enhancement are the main focus of the technical analysis carried out in this study.
\end{abstract}

\section{Introduction}

Voltage stability issues and the extreme problems of indiscriminate voltage collapse remain a crucial challenge to the reliable and economic operation of power systems in Nigeria [1]. According to the Transmission Company of Nigeria, the existing generating capacity of the national grid currently stands at $12,522 \mathrm{MW}$; out of which the average available daily generation is just about 4,000 MW [2]. Only about 59.3\% of the entire population has access to electricity; and the actual national electricity demand is currently above 20,000 MW and still increasing [3]. On the average, more than 20 occurrences of system collapse, both partial and total, is reported yearly in Nigeria [4]. The reason for this has been attributed to the grossly insufficient generation and inadequate transmission network [5]. As it currently stands, the main threat to achieving the Sustainable Development Goals in Nigeria, like in other developing nations, is the problem of poor economy which is principally due to the erratic nature of the energy industry. However, gas-fired distributed generation (DG) technology is helping to change the power system situation in many parts of the world due to cheap source of primary fuel and closeness to the loads. Properly designed DG systems can reduce the risk of stressing the already overloaded transmission lines and improved the system voltage stability [6].

Gas flaring is a common practice that has contributed hugely to both economic losses and environmental degradation within Nigeria. Gas flaring involves the combustion of gas (including useful natural gas) in open flame at oil production sites with no useful mechanism for harvesting useful energy. The economic and environmental impacts assessment of gas flaring has shown that about 47 percent of the total gas produced and 18 percent of the total produced natural gas in Nigeria is flared yearly [7]. An average of about 2.5 billion cubic feet of gas from crude oil production is reportedly being wasted via gas flaring per year in Nigeria [8]. This amounts to credible economic and environmental resources wastage, and has significantly affected the quality of living in terms atmosphere, land and water pollution. However, sufficient amount of useful energy can be produced from gases if proper investment is made on modern and highly efficient natural gas-based energy conversion technologies [9]. By investing in the recent state-of-the-art gas-driven energy technologies and the development of necessary human resources and passing of the petroleum industry bill (PIB), which enables a competitive market for gas sales and ensures better return on investments made on gas infrastructures, Nigeria can rapidly be on her way to economic growth and sustainable development realization.

The renewable technology is still relatively immature in Nigeria, as it is in most of the sub-Saharan African region, due to several reasons ranging from lack of adequate technical know-how to finding suitable sites and obtaining land right-of-way; as well as huge investment financial requirement [10]. However, In [11], it is projected that up to $5000 \mathrm{MW}$ of electricity could be produced daily if the flared estimated 700 million SCF of gas is properly harnessed. A technical and economic analysis of flared gas to electricity potential in Nigeria can help increase the daily direct electricity production by 7500 MW [9]. The transportation Sector, just like the

\footnotetext{
* Corresponding author: adewuyiobode@gmail.com
} 
power sector, can also experience massive transformation by the introduction of efficient natural gas reclamation and gas-to-energy conversion technologies using cleanburning and efficient natural gas-driven vehicles in Nigeria [12]. The lifecycle $\mathrm{CO}_{2}$ emission content of natural gas as primary fuel compared to other energy sources and the possible utilization options for clean natural gases for Nigerian situation is illustrated in Table 1 and Figure 1.
Table 1. Lifecycle $\mathrm{CO}_{2}$ emission intensity [13].

\begin{tabular}{|c|c|}
\hline Fuel source & $\begin{array}{c}\mathbf{C O}_{\mathbf{2}} \text { emmission } \\
\text { (tonnes/GWh) }\end{array}$ \\
\hline Coal & 888 \\
\hline Oil & 733 \\
\hline Natural Gas & $\mathbf{4 9 9}$ \\
\hline Biomass & 450 \\
\hline
\end{tabular}

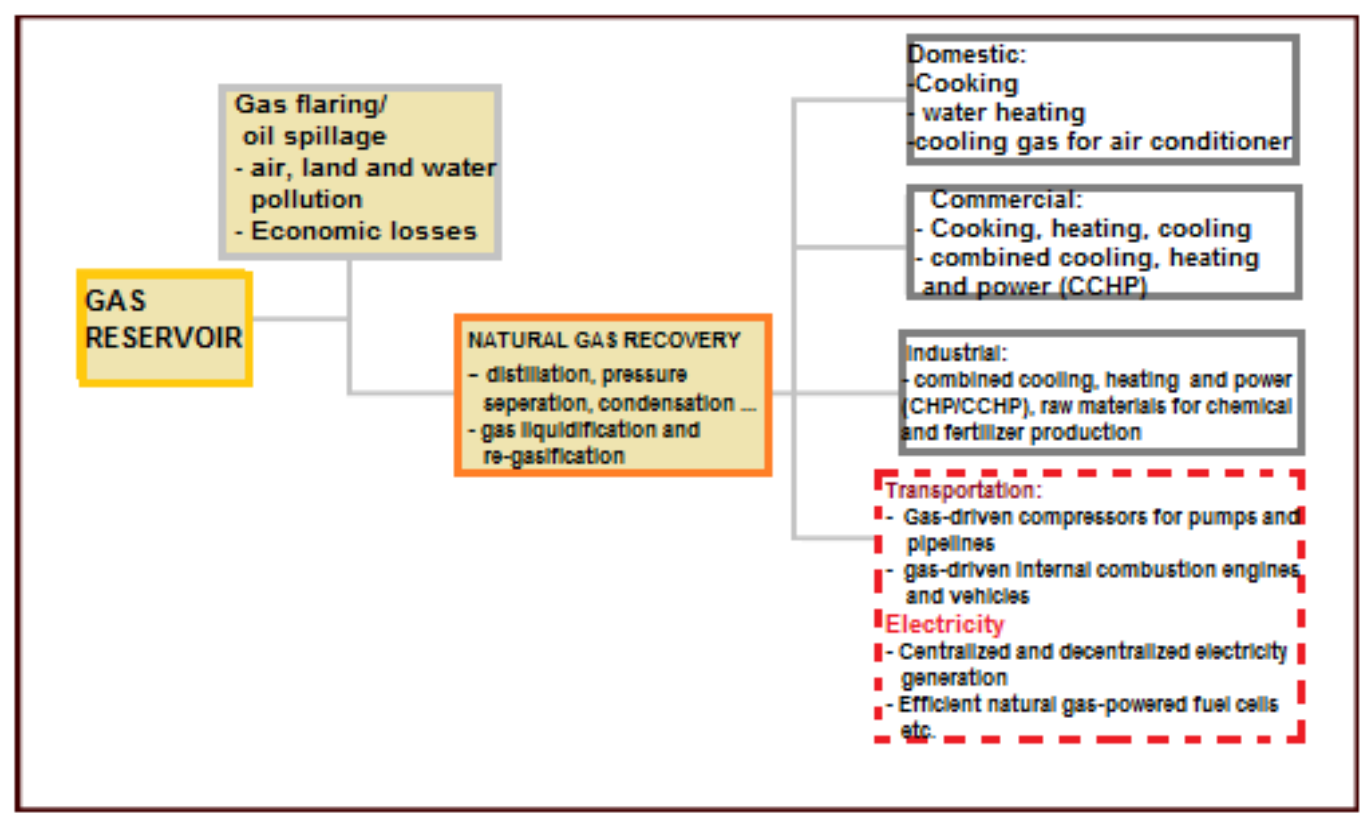

Fig. 1. Possible ways of utilizing natural gas resources for energy production in Nigeria.

\section{Voltage stability and DG injection planning}

The study of the problems (technical and otherwise) that threatens the secure and reliable operation of power systems under different conditions is known as power system stability analysis. Voltage stability problem, also known as Load stability, is a prominent dynamic power system stability issue that is mainly due to the interaction of the power system loading and insufficient generation and reactive power transfer capacity of existing grid infrastructures [14]. Severe voltage instability can appear in a part or the entire power system due to gross inadequacy of the existing generation and transmission facilities. Hence, monitoring the voltage stability conditions of grid networks is crucial for effective planning of additional power injection from DGs. Several major power system's failure (black outs) in recent times are traceable to the problem of voltage collapse. Hence, while planning for increase generation to meet the growing electricity needs, there is a huge need to give adequate consideration to the capacity and condition of the existing grid facility. One important issue to be considered when adding DG units to power systems is the effects it will have on the power flow and voltage stability margin of the power system. This can be observed by monitoring the nearby buses and transmission lines at the point of DG power injection.

\subsection{Effect of DG on voltage stability Margin}

The voltage stability margin is usually estimated as the maximum amount of load increase that a power system can bear without violating the stability condition. It is a measure of the shortest distance from current operating point to the point of voltage collapse as illustrated on Figure 2:

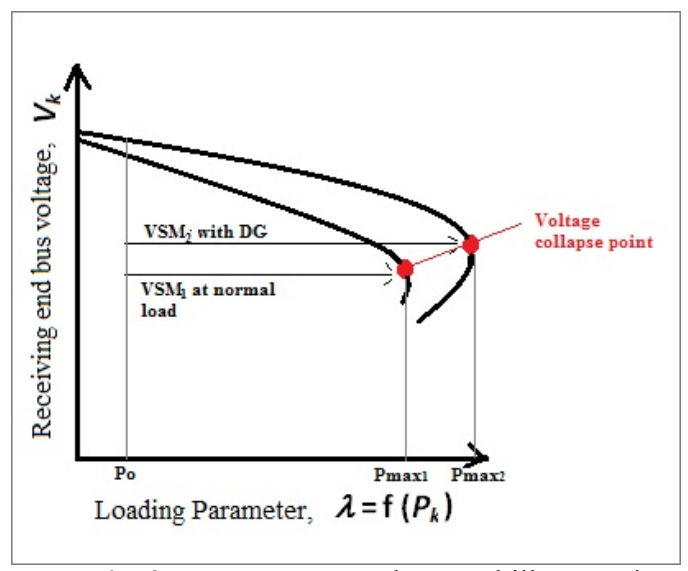

Fig. 2. Power system voltage stability margin 
Considering Figure 3, at any point of DG injection, the net effective demand using the constant PQ load model is :

$$
P_{k}+j Q_{k}=\left(P_{d}-P_{d g}\right)+j\left(Q_{d}-Q_{d g}\right)
$$

(1)

$$
\left(\mathrm{P}_{\mathrm{k}}+\mathrm{jQ} \mathrm{Q}_{\mathrm{k}}\right)=\left(\mathrm{V}_{\mathrm{k}} \angle \delta_{\mathrm{k}}\right)\left(\mathrm{V}_{\mathrm{i}} \underline{\angle \delta_{\mathrm{ik}}} \underset{\mathrm{j}}{\mathrm{r}_{\mathrm{ik}}}-\frac{\mathrm{V}_{\mathrm{k}}}{\mathrm{r}_{\mathrm{k}}} \underline{\delta_{\mathrm{k}}}\right)^{*}
$$

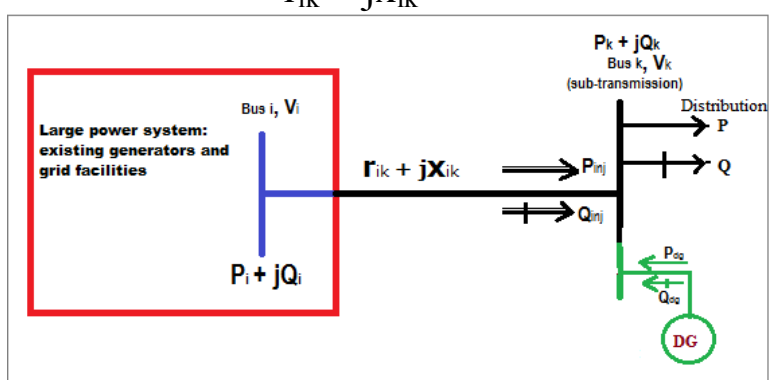

Fig. 3: Illustration of DG injection at a sub-station

Resolving the above equation (2) and separating the real and reactive power components yields:

$$
\begin{array}{r}
\mathrm{P}_{\mathrm{k}} \mathrm{r}_{\mathrm{ik}}+\mathrm{Q}_{\mathrm{k}} \mathrm{x}_{\mathrm{ik}}+\mathrm{V}_{\mathrm{k}}^{2}=\mathrm{V}_{\mathrm{i}} \mathrm{V}_{\mathrm{k}} \cos \left(\delta_{\mathrm{i}-} \delta_{\mathrm{k}}\right) \\
\mathrm{P}_{\mathrm{k}} \mathrm{x}_{\mathrm{ik}}+\mathrm{Q}_{\mathrm{k}} \mathrm{r}_{\mathrm{ik}}=-\mathrm{V}_{\mathrm{i}} \mathrm{V}_{\mathrm{k}} \sin \left(\delta_{\mathrm{i}-} \delta_{\mathrm{k}}\right)
\end{array}
$$

The voltage stability condition of a power system is obtained from algebraic solution of the Eqns. 3 and 4 as [15]:

$$
\sqrt{\left[\left(r_{i k} P_{k}+x_{i k} Q_{k} ? 0.5 V_{i}^{2}\right)^{2}-\left(r_{i k}^{2}+x_{i k}^{2}\right)\left(P_{k}^{2}+Q_{k}^{2}\right)\right]}=0
$$

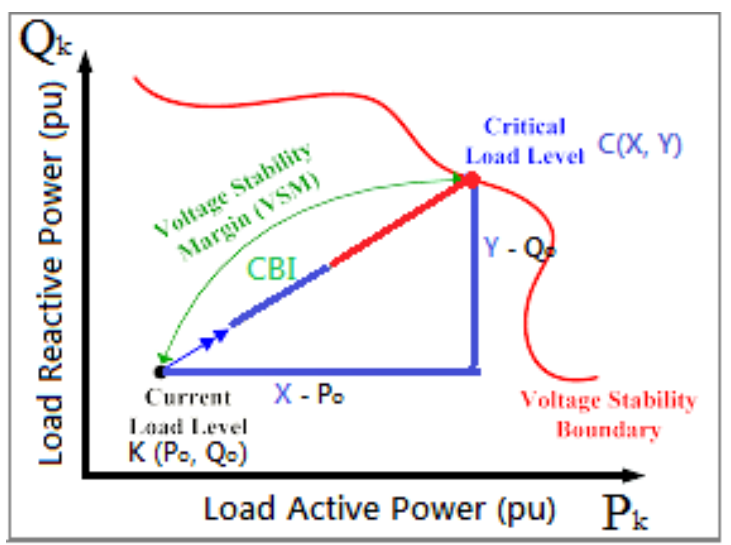

Fig. 4: Voltage stability margin on (P-Q) plane [15].

Figure 4 is a two-dimensional illustration of the real and reactive power loading at the receiving end bus considering a particular bus voltage value. The voltage stability margin, which is the nearest distance of a current operating point, $\mathrm{K}\left(\mathrm{P}_{\mathrm{o}}, \mathrm{Q}_{\mathrm{o}}\right)$ to a point, $\mathrm{C}(\mathrm{X}, \mathrm{Y})$ on critical stability boundary is obtained using the Lagrange multiplier approach as given below :

$$
\begin{aligned}
& F(X, Y, \lambda)=\sqrt{\left(X-P_{o}\right)^{2}+\left(Y-Q_{o}\right)^{2}}+ \\
& \lambda\left[\left(r_{i k} X+x_{i k} Y-0.5 V_{i}^{2}\right)^{2}-\left(r_{i k}^{2}+x_{i k}^{2}\right)\left(X^{2}+Y^{2}\right)\right]
\end{aligned}
$$

The set of equations obtained from the partial derivatives of equation (6) w.r.t. $(\mathrm{X}, \mathrm{Y}, \lambda)$ are solve simultaneously to obtain the maximum (critical) real and reactive power loading $(\mathrm{X}, \mathrm{Y})$, and the corresponding VSM is obtained according to equations (7)-(9) ;

$$
\begin{aligned}
\Delta P & =X-P_{o} \\
\Delta Q & =Y-Q_{o} \\
C B I & =\sqrt{(\Delta P)^{2}+(\Delta Q)^{2}}
\end{aligned}
$$

The closer the CBI value of any of the transmission lines to zero, the closer the power system to voltage collapse.

\subsection{Voltage stability index}

In a more conventional approach, the assessment of power system voltage stability has been achieved by using several mathematical models collectively known as the voltage stability indices [14]. Some of these voltage stability indices are FVSI, NLSI and LQP and their mathematical expressions are given in reference [16]. These tools are used for planning effective enhancement of power system steady-state performances, based on real or/and reactive power optimal rescheduling while considering DG action and other power system enhancement devices. The system is highly unstable and prone to voltage collapse occurrence if the values of NLSI, FVSI and LQP approach 1.0.

\section{Problem Formulation: Gas and electricity optimal power flow (GEOPF)}

\subsection{Objective function}

The mathematical formulation of GEOPF adopted in this work is expressed as a minimization of the total cost of operating the gas-to-grid network infrastructures [17] :

$$
\underset{x}{\operatorname{Minimize}} \mathrm{C}_{\text {total }}(x)=C_{H T}+C_{C G T}+C_{\text {Grid }}+C_{\text {Gpipe }}-C_{g s}
$$

where $\mathrm{C}_{\text {total }}(x)$ is the net cost which consists of the following constituent costs: the conventional hydrothermal generator operating $\operatorname{cost} C_{H T}$, the production and Investment cost on gas turbine $C_{C G T}$, cost of grid enhancement based on additional power injection $C_{G r i d}$, cost of gas pipeline maintenance $C_{\text {Gpipe }}$ and the environmental benefit/sustainability cost of gas (flaring reduction) $C_{g s}$; as expressed below:

$$
C_{H T}=\sum_{i=1, i \neq G}^{n g}\left(a_{i} P_{g i}^{2}+b_{i} P_{g i}+c_{i}\right)
$$




$$
\begin{gathered}
C_{C G T}=\sum_{i=1}^{G}\left(P_{G i} \times K_{G}\right) \\
C_{\text {Grid }}=\sum_{i=1}^{G}\left(P_{G i} \times K_{\text {grid }}\right) \\
C_{\text {Gpipe }}=\sum_{i=1}^{N p i p e}\left(L_{\text {Gpipe }} \times K_{\text {Gpipe }}\right) \\
\text { Cgs }=\sum_{i=1}^{n g s}\left(K_{i}^{\text {net }} \times Q_{\text {gsi }} \times G H V \times 10^{6}\right)
\end{gathered}
$$

$n g$ is the total number of existing hydro-thermal generators, $G$ is the number of selected injection point/combined cycle generating plants, Npipe is the number of pipelines and ngs is the total number of natural gas source points. $a, b$ and $c$ are the quadratic fuel cost coefficients and $P g$ is the active power generated by each unit of the existing generators. $K_{G}$ and $K_{\text {grid }}$ are the corresponding cost per MW of gas plant investment and grid enhancement, respectively. A linear cost model based on the average distance from the oil producing zones to the industrial and commercial zones. $k^{\text {net }}$ is the net cost of gas at each source node in \$/MMBTU. $Q_{g s}$ is the optimal amount of natural gas consumed by the generator in $\mathrm{CF}$ and $\mathrm{GHV}$ is the gas gross heating value in BTU/CF. (BTU means British thermal unit and CF means cubic foot). The cost $k^{\text {net }}$ consists of the actual cost of selling the power from the gas to the grid plus the cost of social benefits in terms of reduced environmental pollution less the cost of selling the gas by the gas suppliers. Hence, the total cost of gas $C_{g s}$ is treated as a positive social benefit which is to be maximized.

\subsection{System constraints}

\subsubsection{Power balance and system limit constraints}

The system generator, bus and line constraints are given in [10]. The negative PQ load model for DG injection analysis is considered for the power balance equation in the load flow analysis [18].

\subsubsection{Voltage stability margin constraint}

To keep the power system secure and within the stability limits, the additional constraints based on the critical stability margin (CBI) is considered as given:

$$
C B I_{i} \geq 0.3 ; i=1,2,3 \ldots n l
$$

$n l$ is the number of transmission lines.

\subsection{Particle Swarm Optimization (PSO) Algorithm with time-varying acceleration coefficient}

The PSO algorithm based on the social behavior and interaction of particles within a swarm is adopted for solving the non-linear optimization problem described in this work; the detail of PSO algorithm is given in [19]. The social and cognitive factors are taken to be varying instead of being constant using the time varying acceleration coefficent (TVAC-PSO) approach described in [20]. Figure 5 is a flowchart that shows the TVACPSO algorithm. The PSO and hydrothermal generator parameters are as given in [10].

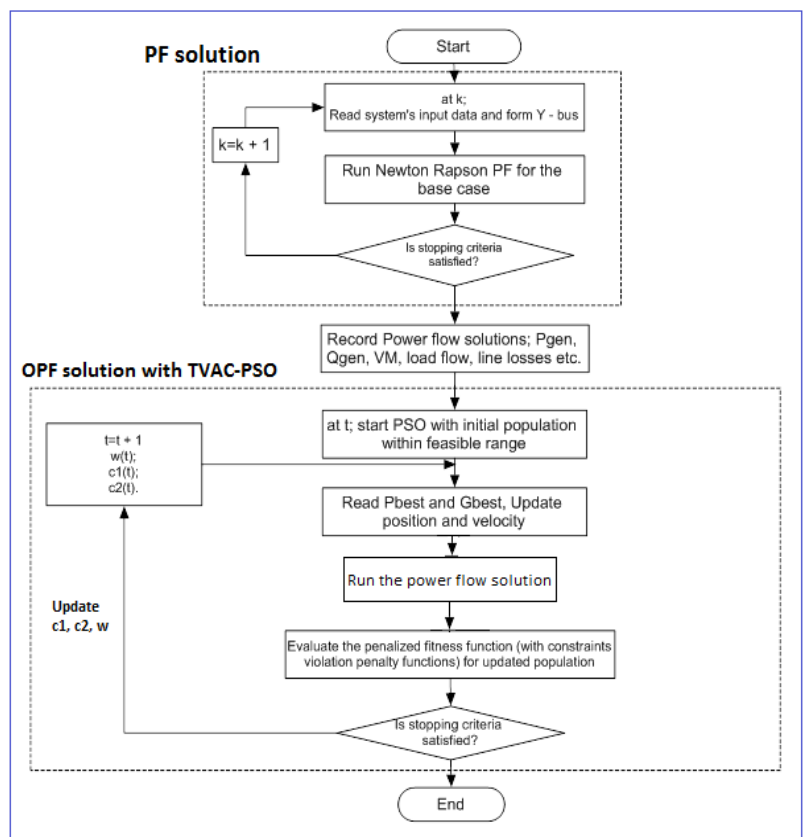

Fig. 5: TVAC-PSO flow chart [20]

The natural gas parameters, using a conversion rate of 3412.14 CF of natural gas $=1 \mathrm{MWh}$ of electricity and $1.00 \mathrm{USD}=360$ Naira, are given in Table 2 .

Table 2. Natural gas data $[7,9]$.

\begin{tabular}{|c|c|}
\hline Symbol & Value (Unit) \\
\hline$K_{G}$ & $1015.00(\$ / \mathrm{kW})$ \\
\hline$K_{\text {grid }}$ & $3.50(\$ / \mathrm{kW})$ \\
\hline$K_{\text {Gipe }}$ & $1.80(\$ / \mathrm{kW})$ \\
\hline$K^{\text {net }}$ & $5.50(\$ / \mathrm{CF})$ \\
\hline$G H V$ & $1150.00(\mathrm{BTU} / \mathrm{CF})$ \\
\hline
\end{tabular}




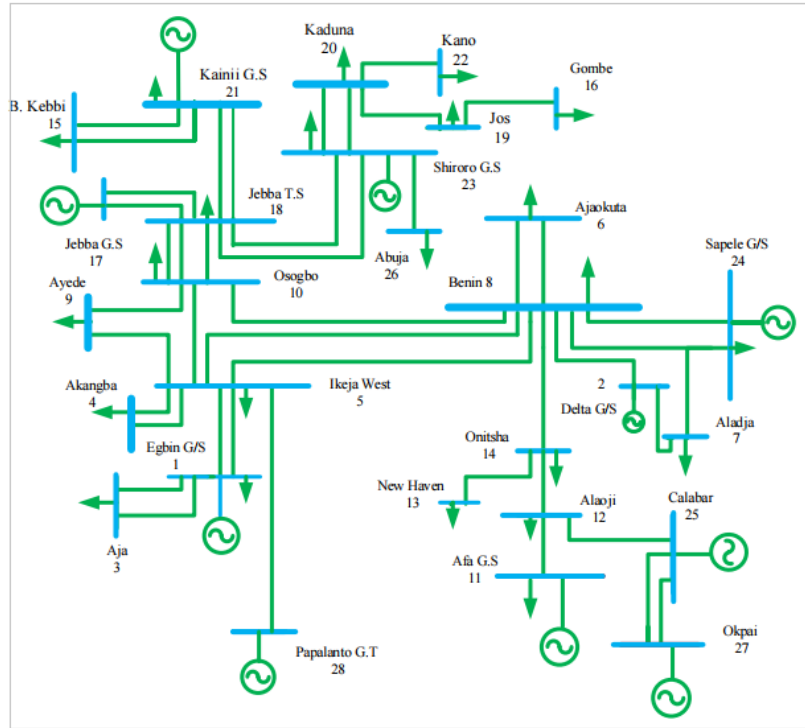

Fig. 6: Nigerian 28 bus Test system

\section{Result and discussion}

The real Nigerian grid, given in Figure 6, at overloaded operating condition is used for the analysis presented in this study. The system has 28 buses and 52 transmission lines. The voltage stability analysis using CBI parameters are used to select DG power injection points, as indicated in Figure 7. Two conditions were considered in selecting the candidate buses; the optimal voltage stability margin of the transmission line described in equation (5)-(9) and the real power loss sensitivity factor, given by equation (16) as obtained from the exact loss formula [18].

$$
L_{f i}=\frac{\partial P_{i k}^{\text {loss }}}{\partial P_{i}}=2 \sum_{k=1}^{N_{b}}\left[\alpha_{i k}\left(P_{k}+\frac{Q_{k}}{\wp}\right)-\beta_{i k}\left(Q_{k}-\wp P_{k}\right)\right]
$$

Where;

$$
\begin{aligned}
\alpha_{i k} & =\frac{r_{i k}}{V_{i} V_{k}} \cos \left(\delta_{i}-\delta_{k}\right) ; \\
\beta_{i k} & =\frac{r_{i k}}{V_{i} V_{k}} \sin \left(\delta_{i}-\delta_{k}\right) \quad \text { and } \wp=\tan \left(\cos ^{-1}(p f)\right)
\end{aligned}
$$

The receiving end buses of the lines with sufficient voltage stability margin (based on real power loadability) and low loss sensitivity are selected. Figure 8 shows the convergence characteristics using TVAC-PSO with optimal total cost of US $\$ 1.285 \times 10^{7}$ with a gas consumption of $6.312 \times 10^{6} \mathrm{SCF}$ (i.e. $Q_{g s}$ ) and injected DG power of $477.45 \mathrm{MW}$ (i.e. $P_{G}$ ). There is a credible improvement in the voltage profile with the placement of DGs as it can be seen on Figure 9. However, there is a need for voltage compensation at the buses 16 and 22 to stay within the set voltage magnitude threshold of 0.95 p.u. The injected power from the gas-fired DGs has plausible improving effects on stability margin of most of the lines, especially the real power stability margin as seen in Figure 10. Also, there is an increase in the optimal stability margin of most of the ill-conditioned lines while all the healthier lines, such as lines 1, 2, 3, 4, 14 etc. remains within the tolerant stability margin.

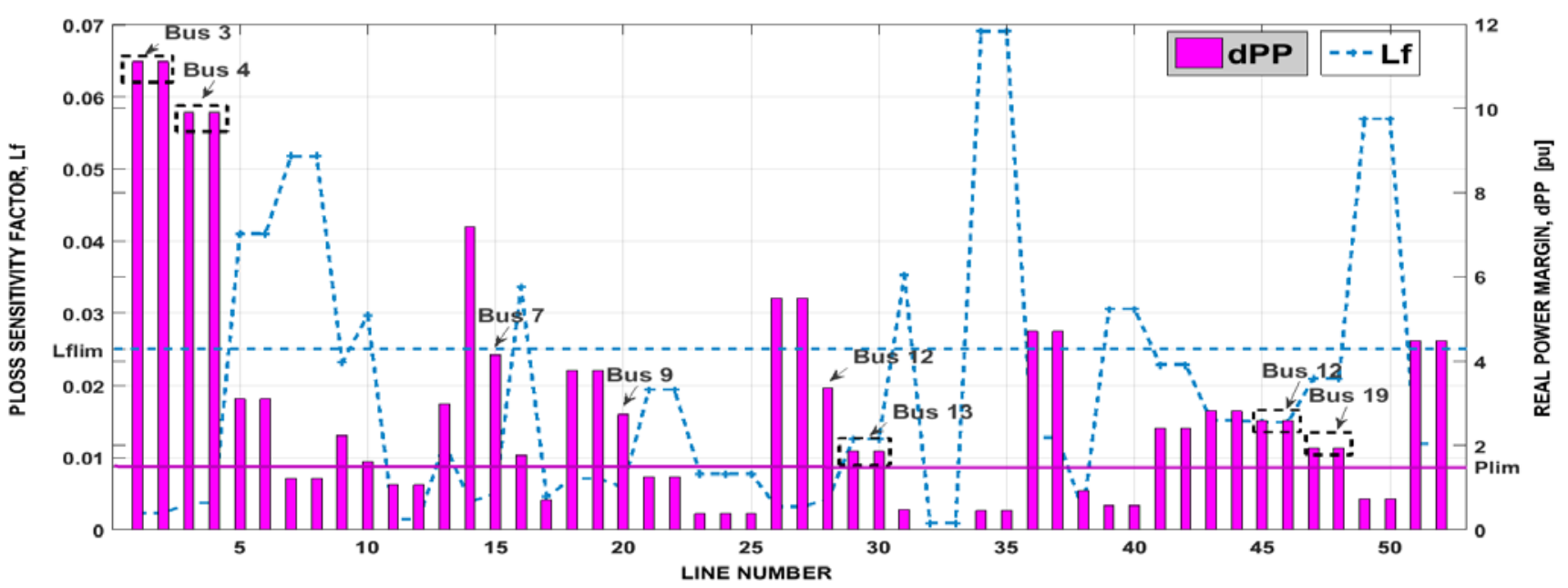

Fig. 7: Identified DG location point 


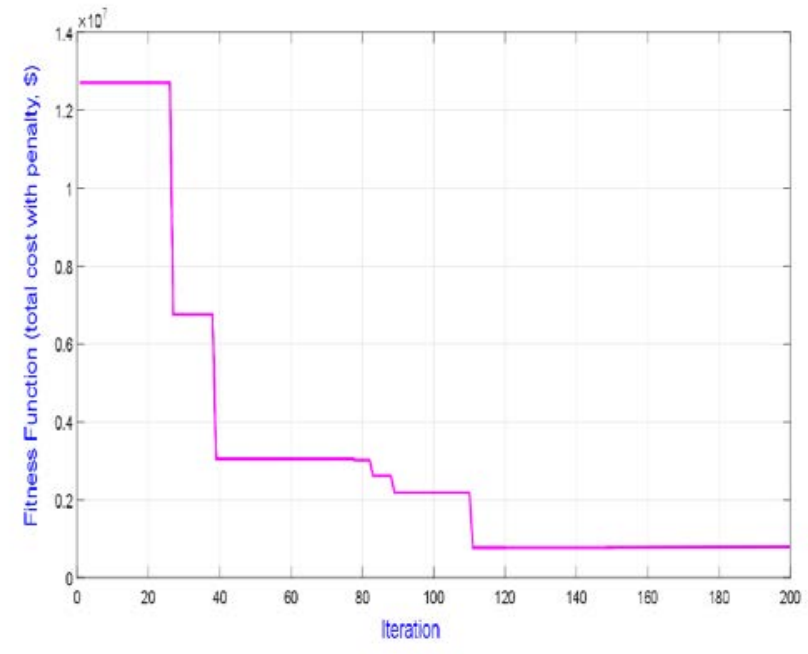

Fig. 8: Convergence characteristics

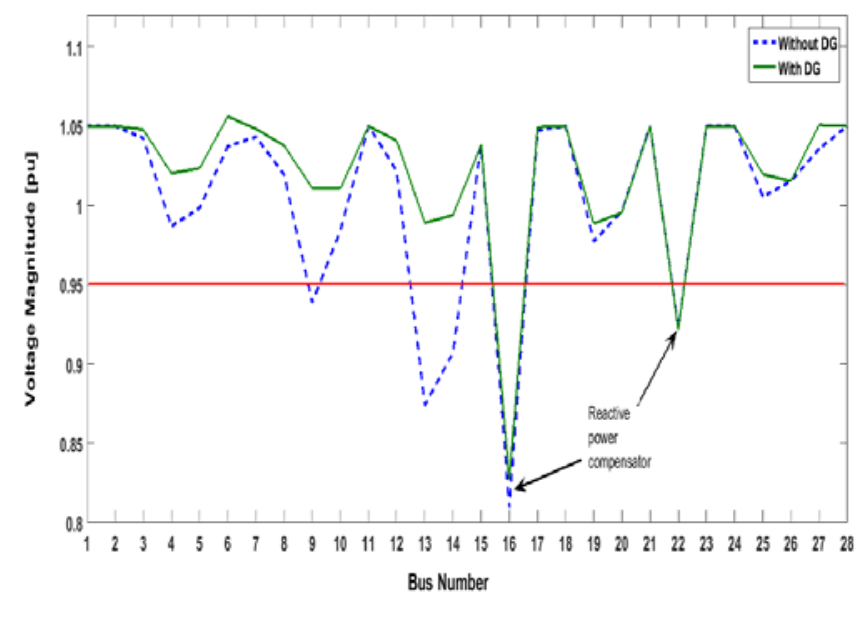

Fig. 9: Bus voltage magnitude
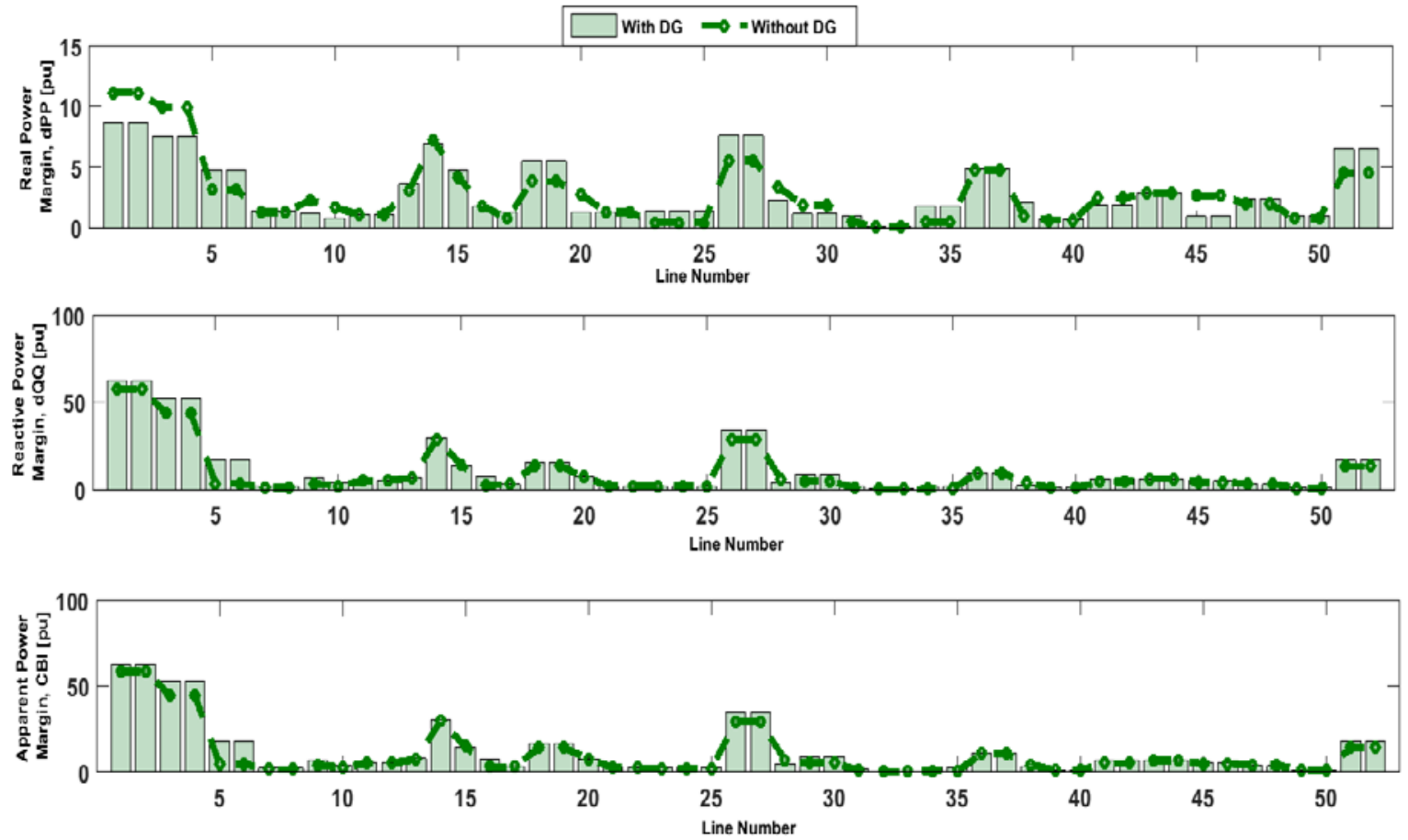

Fig. 10: Effects on optimal stability margin

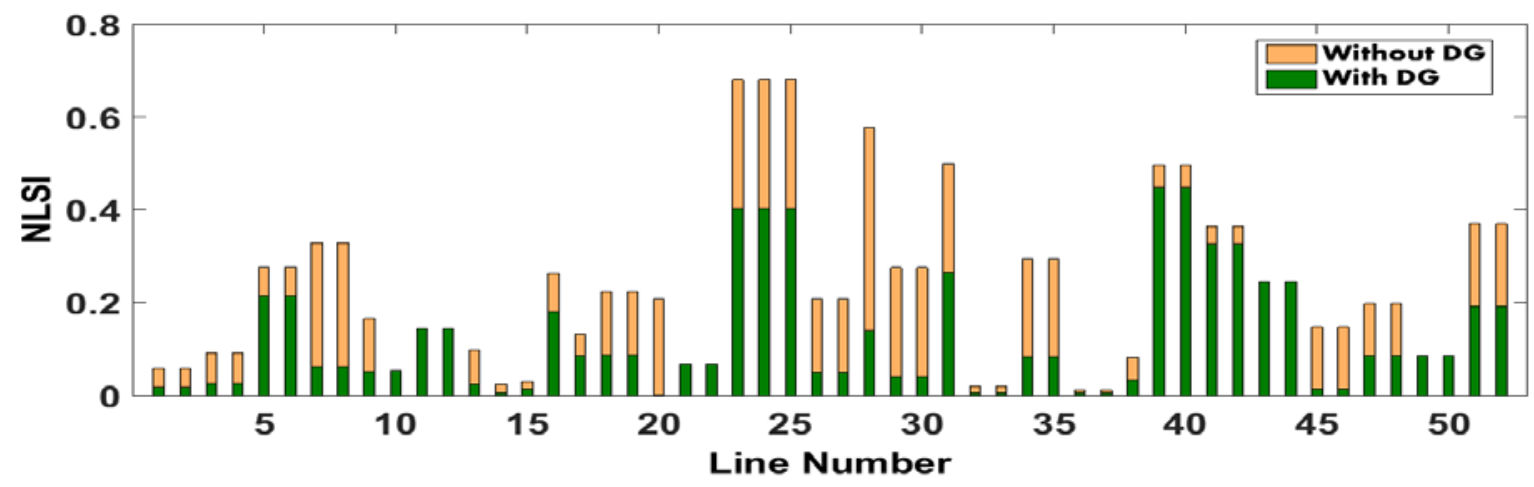

Fig. 11: Voltage stability analysis using NLSI 
The overall influence on the voltage stability condition of the power system was analyzed using the NLSI (equation 17) and presented in Figure 11.

$$
N L S I=4\left(\frac{P_{k} r_{i k}+Q_{k} x_{i k}}{V_{i}^{2} \cos _{\delta}^{2}}\right)
$$

The stability condition of the power system is improved as reflected on the reduction in the NLSI value for almost all the transmission lines. For lines 23, 24 and 25, which are the most critical lines, there is a reduction from 0.7000 to about 0.4023 . This improves the security of the power system and keep it farther away from voltage collapse.

\section{Conclusion}

\section{References}

1. A.O. Ibe, E. Omorogiuwa and I. Kayode, "voltage stability analysis of nigerian power system using distributed generation," Applied Research Journal, vol. 3, issue 2, pp. 53-62, 2017.

2. A. E. Israel, A. A. Enesi, and A. J. Kufre, "Assessment of Nigeria's power situation and the way forward," International Journal of Latest Research in Engineering and Technology, vol. 1, issue 34, pp. 24-31, 2015.

3. Sulaimon Salau, "Nigeria's power demand to hit 88,282 MW by 2020," The Guardian, $\quad$ https://guardian.ng/businessservices/nigerias-power-demand-to-hit-88282mwby-2020/, 2016 [url date: 2016-06-28]

4. U. C. Ogbuefi, C. L. Ugwu and N.O. Ogbogu, "Analysis of Nigeria power system voltage collapse incidences from 2000 to 2017 IOSR Journal of Electrical and Electronics Engineering, vol. 13, number 2, pp. 28-34, 2018.

5. B. O. Akinloye, P. O. Oshevire and A. M. Epemu, "Evaluation of system collapse incidences on the Nigeria power system," Journal of Multidisciplinary Engineering Science and Technology, vol. 3, number 1, pp. 3707-3711, 2016.

6. Sudipta Ghosh, S. P. Ghoshal and Saradindu Ghosh, "Optimal Sizing and Placement of Distributed Generation in a Network System," International Journal of Electrical Power and Energy Systems, vol. 32, 2010, pp. 849-856.

7. O. Adekomaya, T. Jamiru, R. Sadiku, Z. Huan and M. Sulaiman, "Gas flaring and its impact on electricity generation in Nigeria", Journal of Natural Gas Science and Engineering, vol. 29, pp. 1-6, 2016.
Universal access to clean and reliable energy, while keeping the environment pollution-free is a key component of the United Nations' Sustainable Development Goals. Hence, there is currently great interest around the world on the adoption of alternative energy sources, both renewable and non-renewable (clean burning), towards achieving energy and environment sustainability. A techno-economic approach to achieve some of these targets at minimal cost and with positive impact on the immediate environment has been investigated and analyzed in this work, using the Nigerian energy sector situation. The optimization goal is to ensure a voltage-secured use of the existing grid facility and the sustainability goal is to demonstrate how much social, technical and economic benefits can be derived from the judicious use of available energy resources and infrastructures, especially for an oilproducing and developing nation like Nigeria.

8. U. Udok and E. B. Akpan, "Gas flaring in Nigeria: problem and prospects," Global Journal of Politics and Law Research, vol. 5, issue 1, pp. 16-28, 2017

9. E. N. Ojijiagwo, C. F. Oduoza, N. Emekwuru., "Technological and economic evaluation of conversion of potential flare gas to electricity in Nigeria". Procedia Manufacturing 17, 444-451, 2018.

10. O.B. Adewuyi, M.E. Lotfy, B.O. Akinloye, H.O.R. Howlader, T. Senjyu and K. Narayanan, "Securityconstrained optimal utility-scale solar PV investment planning for weak grids: Short reviews and technoeconomic analysis", Applied Energy, Vol. 245, pp. 16-30,2019.

11. M. Eboh, "Nigeria losing N $868 \mathrm{~m}$ daily to gas flaring,"

https:/www.vanguardngr.com/2018/03/nigerialosing-n868m-daily-gas-flaring-nnpc/, accessed: 2019-02-08].

12. S. O. Giwa, C. N. Nwaokocha, B.O. Odufuwa, "Mitigating gas flare and emission footprints via the implementation of natural gas vehicles in Nigeria". Energy Policy 111, 193-203, DOI: https://doi.org/10.1016/j.enpol.2017.09.027, 2017.

13. WNA, Comparison of lifecycle greenhouse gas emissions of various electricity generation sources, 2011. http://www.worldnuclear.org/uploadedFiles/org/WNA/Publications/W orking_Group_Reports/comparison_of_lifecycle.pdf

14. O. B. Adewuyi, M. S. S. Danish, A. M. Howlader, T. Senjyu and M. E. Lotfy, "Network structure-based critical bus identification for power system considering line voltage stability margin," Journal of Power and Energy Engineering, vol. 6, pp. 97-111, 2018.

15. M. Furukakoi, O. B. Adewuyi, M. S. S. Danish, A. M. Howlader, T. Senjyu and T. Funabashi, "Critical 
Boundary Index (CBI) Based on Active and Reactive Power Deviations," International Journal of Electrical Power and Energy Systems, vol. 100, issue 1, pp. 50-57, 2018.

16. M. S. S. Danish, A. Yona and T. Senjyu, "A Review of Voltage Stability Assessment Techniques with an Improved Voltage Stability Indicator," International Journal of Emerging Electric Power Systems, vol. 16, issue 2, pp. 107-115, 2015.

17. S. An, "Natural Gas and Electricity Optimal Power Flow", Ph.D. Thesis, Oklahoma State University, USA, 2004.

18. A. Tah. and D. Das: "Novel Analytical Method for the Placement and Sizing of Distributed Generation unit on Distribution Networks with and without considering P and PQV buses", International Journal of Electrical Power and Energy Systems, vol. 78, pp. 401-413, 2016

19. J. Kennedy and R. Eberhart: "Particle Swarm Optimization", IEEE International Conference on Neural Networks, vol. 4 pp. 1942 - 1948, 1995

20. A. Ratnaweera A., S. K. Halgamuge and H. C. Watson, "Self-Organizing Hierarchical Particle Swarm Optimizer with Time-Varying Acceleration Coefficients", IEEE Transactions on Evolutionary Computation, Vol. 8, Issue 3, pp. 240 - 255, 2004. 